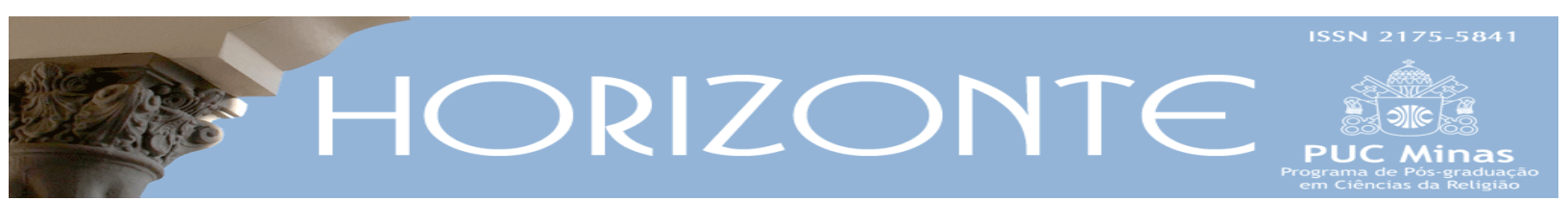

Dossiê: Religião e Educação - Artigo original ๑을

DOI - 10.5752/P.2175-5841.2020v18n55p106

\title{
Ensino Religioso: \\ por uma prática que promova conscientização
}

\author{
Religious Education: \\ for a practice that promotes awareness
}

Julio Cezar de Paula Brotto*

Valdir Stephanini*

\begin{abstract}
Resumo
Reconhecendo que a presença da disciplina Ensino Religioso Escolar em escolas públicas de Ensino Fundamental no Brasil é um assunto complexo e polêmico, é de fundamental importância que se busque alternativas para que sua oferta se dê de tal forma a possibilitar o surgimento de pessoas conscientes e participativas no processo de transformação da sociedade. Foi em busca desse objetivo que os autores desse artigo encontraram na categoria da conscientizaçãa, proposta por Paulo Freire, um caminho possível para que professores e professoras da disciplina Ensino Religioso das escolas públicas brasileiras contribuam para a formação de cidadãos e cidadãs autônomos/as, a partir da aquisição de uma consciência crítica, capazes de fazerem suas próprias escolhas, com plena liberdade. Metodologicamente o artigo foi organizado a partir do método Ver, Julgar e Agir. Este método de análise permite olhar a realidade socioeconômica, política e cultural na qual as pessoas encontram-se inseridas, confrontar com determinado instrumental teórico, com o objetivo de propor possíveis caminhos e alternativas para a promoção de uma educação libertadora. Desta forma, na primeira seção, intitulada Norteando o olhar, foram apresentadas duas categorias teóricas relativas à educação, a saber: educação bancária e educação libertadora. Na segunda, Definindo o olhar buscou-se tecer uma abordagem em torno da categoria da conscientização, proposta por Paulo Freire. Na terceira seção, Desvendando o olhar, os autores apresentam possíveis caminhos de ação para uma educação libertadora a partir do ensino da disciplina de Ensino Religioso.
\end{abstract}

Palavras-chave: Conscientização. Ensino Religioso. Paulo Freire.

\begin{abstract}
Recognizing that the presence of the Religious School Teaching discipline in public elementary schools in Brazil is a complex and controversial subject, it is of fundamental importance that alternatives be sought so that its offer takes place in such a way as to enable the emergence of conscious and participatory people in the process of transforming society. It was in pursuit of this objective that the authors of this article found in the category of conscientização, proposed by Paulo Freire, a possible way for teachers of the Religious Education discipline of Brazilian public schools to contribute to the formation of autonomous citizens, with a critical conscience, capable of making their own choices, with full freedom. Methodologically, the article was organized using the See, Judge and Act method. This method of analysis allows us to look at the socioeconomic, political and cultural reality in which people are inserted, to confront a specific theoretical instrument, with the aim of proposing possible ways and alternatives for the promotion of a liberating education. Thus, in the first section analyzes two theoretical categories related to education, namely: banking education and liberating education. In the second section, an attempt was made to weave an approach around the category of conscientização, proposed by Paulo Freire. In the third section, the authors present possible paths of action for a liberating education based on the teaching of Religious Education.
\end{abstract}

Keywords: Awareness. Religious Education. Paulo Freire.

Artigo submetido em 27 de novembro de 2019 e aprovado em 2 de abril de 2020.

* Doutor em Teologia pela PUC-Rio. Professor da Faculdade Unidade de Vitória. País de origem: Brasil. E-mail: julio.brotto@fuv.edu.br

** Doutor em Teologia pela PUC-Rio. Professor da Faculdade Unidade de Vitória. País de origem: Brasil. E-mail: valdir@fuv.edu.br 


\section{Introdução}

O Brasil passa por um momento de polarização político-religiosa que também pode ser observado em outros países da América do Sul e no mundo todo. Veja a recente situação da Bolívia com demonstração política vinculada a uma determinada leitura e interpretação religiosa (AFP, 2019). No Brasil, as trocas no comando do Ministério da Educação causam perplexidade. Desde o início da atual gestão presidencial, três ministros assumiram o Ministério da Educação (MEC). Neste tempo a pasta foi administrada por titulares de diferentes perfis e estagnou ou mesmo retrocedeu em sua atuação. Chegou-se recentemente ao quarto ministro apresentado pela imprensa nacional como “professor e pastor” (G1, 2020).

Em certo sentido esta polarização reforça uma prática de ministrar a disciplina Ensino Religioso nas escolas públicas de Ensino Fundamental no Brasil pelo viés confessional. Desde já é preciso esclarecer como serão abordadas as categorias teóricas Ensino Religioso e confessionalidade.

Entendem os autores, que Ensino Religioso refere-se ao que está definido no artigo 210, parágrafo $1^{\circ}$, da Constituição Federativa do Brasil (BRASIL, 2019. p. 168), reafirmado pela Lei de Diretrizes e Bases da Educação no artigo 33, parágrafos $1^{\circ}$ e $2^{\circ}$ (LDB, 2018, p. 23-24). Também é preciso levar em consideração a Base Nacional Comum Curricular que descreve a área de Ensino Religioso (MEC, 2017, 435-458). Na abertura da descrição está afirmado:

Ao longo da história da educação brasileira, o Ensino Religioso assumiu diferentes perspectivas teórico-metodológicas, geralmente de viés confessional ou interconfessional. A partir da década de 1980, as transformações socioculturais que provocaram mudanças paradigmáticas no campo educacional também impactaram no Ensino Religioso. (MEC, 2017, p. 435).

Tomando-se esse trecho acima da BNCC é possível perceber que houve preocupação do legislador em destacar que o Ensino Religioso foi compreendido por aproximações teórico-metodológicas confessionais. Mais adiante o documento chama a atenção para o fato que: 
A Constituição Federal de 1988 (artigo 210) e a LDB nº 9.394/1996 (artigo 33, alterado pela Lei $n^{0}$ 9.475/1997) estabeleceram os princípios e os fundamentos que devem alicerçar epistemologias e pedagogias do Ensino Religioso, cuja função educacional, enquanto parte integrante da formação básica do cidadão, é assegurar o respeito à diversidade cultural religiosa, sem proselitismos. (MEC, 2017, p. 435).

Destaque deve ser dado à expressão sem proselitismos. Acrescente-se a esta a firmação o fato de que elaboração da área do Ensino Religioso buscou natureza e finalidades pedagógicas distintas da noção de confessionalidade (MEC, 2017, p. 435). Novamente se faz necessário que os autores indiquem como compreendem, para os fins deste artigo, a categoria confessionalidade. Considerando que os séculos XVI e XVII apresentam-se como um marco na História da Educação e que a noção de confessionalidade configura-se a partir da práxis pedagógica da igreja, tanto no campo católico como no protestante, é possível afirmar que o discurso educativo não raras vezes se confunde com o discurso teológico (OLIVEIRA, 2016, p. 90). Quando se apresenta a noção de confessionalidade têm-se como pressuposto certa confusão que pode ocorrer entre o discurso teológico, doutrinário e catequético vinculado a uma determinada denominação, no caso brasileiro, geralmente religiões de matriz cristã.

A despeito dos esforços do Fórum Nacional Permanente do Ensino Religioso (FONAPER) de promover uma reflexão epistemológica em torno dos conteúdos da disciplina desde 1995, é possível perceber, até mesmo nos relatos do senso comum das pessoas, o vínculo confessional de docentes que imprimem um caráter confessional ou doutrinário às aulas da disciplina Ensino Religioso. Já em 1997 o FONAPER afirmava que "[...] o fenômeno religioso é a busca do Ser frente à ameaça do Não ser." (FONAPER, 2004, p. 32).

É possível supor, porque este artigo não se debruçou numa avaliação estatística, que em função de ser o Brasil um país onde as pessoas se identificam religiosas nos Censos Demográficos, a julgar pelos dados fornecidos pelo Instituto Brasileiro de Geografia e Estatística (IBGE), que a maioria dos professores e professoras da disciplina Ensino Religioso, provavelmente sejam religiosos e 
religiosas. Os resultados do Censo Demográfico 2010 demonstram o aumento da diversidade dos grupos religiosos no Brasil, manifestando uma maior pluralidade nas regiões mais urbanizadas e populosas.

Considerados apenas os percentuais dos Sem Religião e Não sabe/não declarou encontramos uma parcela pequena da população que não relata uma pertença religiosa (IBGE, 2012, p. 90,92). Os autores, por uma questão de valorizarem seus pertencimentos religiosos, também valorizam os pertencimentos religiosos de todos os professores e professoras que ministram a disciplina Ensino Religioso no Brasil. Contudo, compreendem que a pertença religiosa ou confessionalidade não pode interferir na prática pedagógica tornando-se uma espécie de catequese ou ensino doutrinário.

Buscar a não confessionalidade ou no exercício do magistério deveria ser uma atitude normal e até natural, pois esta atitude visa assegurar o respeito à diversidade religiosa no dia a dia das pessoas, inclusive no ambiente escolar. É fundamental consolidar uma prática educacional que dê tratamento adequado à questão da diversidade cultural religiosa brasileira, com base em conceitos como respeito, liberdade religiosa, laicidade e convivência democrática.

Este artigo, que metodologicamente está estruturado a partir do método Ver, Julgar e Agir analisa o pensamento de Paulo Freire a partir do construto conscientização, para propor que a conscientização do/a docente da disciplina Ensino Religioso redundará num processo educacional libertador em oposição a uma prática amplamente utilizada que promove uma educação domesticadora.

\section{Norteando o olhar: educação bancária versus educação libertadora}

Esta seção propõe dar um norte à temática em estudo, uma direção investigativa, assumindo metodologicamente a posição de Ver. Serão abordados os conceitos educação bancária versus educação libertadora que nortearam a investigação e contribuíram para analisar o pensamento de Paulo Freire sobre o processo educacional. 
Educador brasileiro, destacado em âmbito nacional e internacional, Paulo Freire (1921-1997) colaborou significativamente para a conscientização de inumeráveis educadores e educadoras que se envolveram com a educação em diversos níveis. Ficou conhecido especialmente pelo desenvolvimento de um método de alfabetização que é mencionado como Método Paulo Freire. Embora não seja a intenção dos autores analisarem como Paulo Freire desenvolve seu método de alfabetização, expresso na obra Pedagogia do Oprimidoํㅜ a obra Educação como Prática de Liberdade é de extraordinária importância para a fundamentação da pedagogia freiriana e precisa ser rapidamente lembrada. Nela se acham estruturadas e ampliadas reflexões de sua sistematização metodológica que permitem a sua concretização enquanto método pedagógico (FREIRE, 1967). Afirma Freire sobre o método:

Mas, como realizar esta educação? Como proporcionar ao homem meios de superar suas atitudes, mágicas ou ingênuas, diante de sua realidade? [...] A resposta nos parecia estar: a) num método ativo, dialogal, crítico e criticizador; [...] Somente um método ativo, dialogal, participante, poderia fazê-lo. (FREIRE, 1967, p. 107).

Sua tese fundamental está baseada na concepção de que a educação pode ser utilizada como um instrumento de domesticação ou de libertação. A vida, a obra e o envolvimento de Paulo Freire com a educação popular é o depoimento de que ele buscava e proclamava uma possibilidade de educar, embasada numa solidariedade vivida em prol do outro. Henry Giroux, educador e amigo de Paulo, assinala esta solidariedade na obra e vivência de Freire.

Na experiência vivida de Paulo nós vimos uma afirmação fantástica da solidariedade humana enquanto em suas palavras nós somos confortados com a possibilidade de tornar esta solidariedade não meramente uma memória muito querida e encantadora, mas parte de uma comunidade em amor (GIROUX, 2009, p. 17).

\footnotetext{
${ }^{1}$ Paulo Freire terminou a redação desta que é a sua mais conhecida obra enquanto estava no exílio, no Chile, em 1968. Em função da desavença política entre a ditadura militar e o pensamento de Paulo Freire, o livro só foi publicado no Brasil em 1974.
} 
A relevância de Paulo Freire não reside apenas na contribuição que ele deu para a educação de adultos, ou no próprio método em si, mas nas possibilidades que são abertas através da aplicação de seu pensamento relacionado à educação. $\mathrm{O}$ Método Paulo Freire foi a principal causa do aprisionamento de Freire em 1 de abril de 1964, mas seu radicalismo e subversividade foram derivados de algo mais profundo como ele mesmo afirmou: "[...] meu crime real foi que eu tratei a alfabetização como mais do que um problema mecânico e ligava isso à conscientização, que era perigosa.” (FREIRE, 1976, p. 57). ${ }^{2}$

Freire advogava duas abordagens educacionais, a partir dos conceitos que sempre confrontou: educação bancária versus educação libertadora. A característica central da educação bancária é a ênfase na memorização. Para Freire, "é puro treino, é pura transferência de conteúdo, é quase adestramento, é puro exercício de adaptação ao mundo" (FREIRE, 2000, p. 101). É um processo mecânico em que a participação dos alunos e alunas é limitada a receber, arquivar ou armazenar o conhecimento que é depositado ou transferido pelo/a professor/a. Fundamental para o conceito de educação bancária é a compreensão dos seres humanos como seres gerenciáveis. A abordagem é a antítese do conceito de educação libertadora.

O conceito de educação bancária é impeditivo de promoção do diálogo, pelo fato de que "o educador é o que diz a palavra; os educandos, os que a escutam docilmente; o educador é o que disciplina; os educandos, os disciplinados" (FREIRE, 2005, p. 68). Pode-se afirmar que aquele que transgride não é o que educa, porém sempre será aquele que é educado, pois tem que ser educado para não transgredir as regras estabelecidas. A metáfora bancária está relacionada ao ato de depositar como ocorre numa agência financeira. $\mathrm{O} /$ a educador/a considerase como aquele/a que tem os recursos para depositar conteúdos nas cabeças dos/as discentes, tomando-os/as como se fossem receptáculos que precisam ser entupidos com as descobertas alheias a despeito de suas próprias descobertas. Esta educação

\footnotetext{
2 "my actual crime was that I treated literacy as more than a mechanical problem and linked it to conscientização, which was dangerous". (tradução nossa).
} 
bancária não pode ser considerada libertadora, mas precisa ser denunciada como opressora, pois não promove a conscientização dos/as discentes. Esta educação gera docentes inconscientes e sujeitos às normas, que reforçam e perpetuam uma relação educacional autoritária e vertical. Educadores e educadoras não podem se optar por uma educação meramente pragmática (FREIRE, 2000, p. 108).

$\mathrm{Na}$ educação bancária, os/as discentes não são convocados ao saber/aprender, mas ao processo de memorizar, decorar. Na educação libertadora, os/as discentes são incluídos como participantes ativos do processo de resolução de problemas; não são agora meros ouvintes submissos, mas co-investigadores críticos em diálogo com o/a docente. Agora são convocados a descobrirem ativamente o objeto de seu conhecimento, a pensar em vez de memorizar. Enquanto uma educação bancária propõe a fragmentação da consciência, a educação libertadora propõe a emergência da consciência. A este respeito Freire afirma:

[...] a educação libertadora, problematizadora, já não pode ser o ato de depositar, ou de narrar, ou de transferir, ou de transmitir "conhecimentos" e valores aos educandos, meros pacientes, à maneira da educação "bancária", mas um ato cognoscente. [...] O antagonismo entre as duas concepções, uma, a "bancária", que serve à dominação; outra, a problematizadora, que serve à libertação, toma corpo exatamente aí. Enquanto a primeira, necessariamente, mantém a contradição educadoreducando, a segunda realiza a superação. (FREIRE, 2005, p. 78).

Uma educação libertadora torna-se diferente de uma educação domesticadora, pois este tipo de educação não admite o ser humano desconectado do mundo em que vive, já que a realidade é feita pelos próprios seres humanos. Se os seres humanos "são estes seres da busca e se sua vocação ontológica é humanizar-se, podem, cedo ou tarde, perceber a contradição em que a 'educação bancária' pretende mantê-los e engajar-se na luta por sua libertação.” (FREIRE, 2005, p. 71). O papel do/a docente na educação libertadora é criar, juntamente com os/as discentes, as condições sob as quais o conhecimento doxa possa ser substituído pelo conhecimento logos. Nessa perspectiva, o processo educacional torna-se a revelação da consciência crítica, pois a aprendizagem consiste em 
problematizar realidade. $\mathrm{O} / \mathrm{a}$ docente já não é mais o detentor do conhecimento, pois o conhecimento é um processo e o processo educacional se torna um processo de transformação, em vez de transferência de conhecimento. A educação libertadora rompe com o padrão vertical da educação bancária e a substitui por uma relação horizontal entre discente e docente, caracterizada pelo diálogo.

Num primeiro momento, parece improvável que a obra do educador brasileiro que desenvolve um método de alfabetização projetado para ensinar adultos a ler em menos de quarenta e cinco dias pode ter relevância para se refletir sobre a disciplina Ensino Religioso. Contudo, vale ressaltar que a disciplina Ensino Religioso pressupõe o estudo de conhecimentos religiosos, relações interculturais e inter-religiosas, com vistas a uma formação integral, promotora de cidadania e direitos humanos. Logo, se a disciplina Ensino Religioso for ministrada a partir do conceito de educação libertadora em vez do conceito de educação bancária, os/as discentes certamente contribuirão na promoção do respeito, tolerância e convívio democrático entre pessoas/grupos religiosos/as e não-religiosos/as.

Um dos enormes desafios da disciplina Ensino Religioso é ofertar uma prática de ensino-aprendizagem voltada para a superação do tradicional caráter confessional, catequético, doutrinário e religioso histórica da disciplina, de forma que seja possível construir e consolidar o respeito e a tolerância à diversidade cultural e religiosa. Imprimir caráter catequético e doutrinário, como aconteceu durante os períodos do Brasil Colônia e do Brasil Império, instiga percepções de mundo que excluem e ações de falta de respeito às diferenças culturais e religiosas.

A perspectiva radical de Freire pode ser uma contribuição enriquecedora para docentes da disciplina Ensino Religioso, pois tem a capacidade de ser verdadeiramente libertadora, pelo fato de estar centrada no conceito de aprendiz autônomo. Mas, todo este processo precisa ter início na conscientização do/a docente da disciplina. Neste sentido na próxima seção propõe-se olhar a categoria teórica conscientização como processo caracterizado pela crença na criatividade do espírito humano e um compromisso sustentado com a possibilidade de 
desenvolvimento do/a discente autônomo/a. Logo, aqui o foco não recai sobre o/a discente, mas, sim, no/a docente, visto que este precisa vivenciar o processo de conscientização.

\section{Definindo o olhar: a categoria teórica conscientização}

A presente seção analisa a categoria teórica conscientização, a partir da proposição de Paulo Freire. Metodologicamente, como esta seção refere-se ao Julgar, foi apresentado o enfoque teórico. Observando as constatações do Ver, volta-se para o enfoque teórico em busca de definir a categoria teórica conscientização face ao desafio de educar para libertar.

Não obstante Paulo Freire ser considerado o autor do termo conscientização, na realidade foi Dom Helder Câmara quem traduziu o termo para a língua inglesa e francesa e o divulgou. "Desde então, esta palavra forma parte de meu vocabulário. Mas foi Hélder Câmara quem se encarregou de difundi-la e traduzi-la para o inglês e para o francês" (FREIRE, 1979, p. 15). A origem do termo conscientização descrita por Paulo Freire está intimamente ligada ao Instituto Superior de Estudos do Brasil:

Acredita-se geralmente que sou autor deste estranho vocábulo "conscientização" por ser este o conceito central de minhas idéias sobre a educação. Na realidade, foi criado por uma equipe de professores do INSTITUTO SUPERIOR DE ESTUDOS BRASILEIROS por volta de 1964. Pode-se citar entre eles o filósofo Álvaro [Vieira] Pinto e o professor Guerreiro [Ramos]. Ao ouvir pela primeira vez a palavra conscientização, percebi imediatamente a profundidade de seu significado, porque estou absolutamente convencido de que a educação, como prática da liberdade, é um ato de conhecimento, uma aproximação crítica da realidade. (FREIRE, 1979, p. 15).

As categorias conscientização e educação libertadora se intercruzam, se perpassam e se complementem. No entrecruzamento da proposta de uma educação libertadora com a figura do/a docente, conscientização e educação libertadora devem ser complementares enquanto categorias ético-político-pedagógicas. 
Da sua formação católica cristã Paulo trouxe algumas influências para a sua literatura educacional, entre outras, as virtudes teologais. Entretanto, devo alertar, estas virtudes foram superadas em categorias ético-políticopedagógicas na sua compreensão de educação. Podemos facilmente constatar a Fé, relida por ele na crença nos homens e nas mulheres; a Esperança, que embora tenha permanecido com a mesma palavra, ganhou nele nova acepção diante de sua percepção da incompletude humana e capacidade de sonhar com a utopia no sentido de viabilizarmos o Ser Mais, para concretizarmos a verdadeira existência humana; e a Caridade, que se transmutou em solidariedade. Solidariedade para com o mundo, para com a sustentabilidade do Planeta Terra, porque esta implica na mais profunda solidariedade para com todos os homens e mulheres do mundo. (FREIRE; FREIRE; OLIVEIRA, 2009, p. 41).

Estas categorias ético-político-pedagógicas podem estar na base de uma educação libertadora de modo a aprofundar a crença nos homens e mulheres, viabilizando a verdadeira existência humana e promovendo uma revolução de solidariedade nos/as discentes.

É preciso deixar claro que a categoria conscientização é, para Freire,

um dos seus eixos estruturantes mais importantes, porque, para ele, a alfabetização só se dá, quando o(a) alfabetizando(a) se conscientiza criticamente sobre os contextos em que vive. Em síntese, a alfabetização linguística só é possível com a "conscientização política", que se dá com a leitura crítica do mundo. (MARINHO, 2015, p. 93).

Outro aspecto importante que deve ser destacado é que a categoria teórica conscientização acabou por receber usos inadequados e inoportunos, até mesmo por aqueles que defendiam a educação bancária. Em função da idealogização ou manipulação da categoria, em determinada altura de sua vida, Freire decidiu não usar o vocábulo.

Você me indaga sobre o ter deixado de fazer referências diretas à palavra conscientização. É verdade. A última vez em que me estendi sobre o tema foi em 1974. [...] Tive, indiscutivelmente, razões para desusar a palavra. Nos anos 70, com exceções, é claro, falava-se ou se escrevia de conscientização como se fosse ela uma pílula mágica a ser aplicada em doses diferentes com vistas à mudança do mundo. (FREIRE, 1995, p. 112). 
Os autores deste artigo correm o risco de serem incluídos na lista daqueles que usam a categoria conscientização de maneira equivocada. Contudo, correm o risco de maneira consciente, buscando uma analogia com o pensamento de Freire. Por analogia, pode-se afirmar que a conscietização do/a docente só ocorrerá na medida em que o/a próprio/a docente se conscientize criticamente sobre os contextos em que vive. Se a alfabetização linguística só é possibilitada em função da conscientização política, que ocorre por meio de uma leitura crítica do mundo, a alfabetização profissional do/a docente só ocorrerá por meio de sua conscientização política, que ocorre por meio de uma leitura crítica do mundo. Que mundo tem o/a docente da disciplina Ensino Religioso diante de seu olhar? Quem são os/as discentes que este/a profissional da educação tem diante de si? Quais são suas angústias? Quais são seus medos? Quais são suas razões de viver e de até não viver?

Se a leitura e interpretação que os autores deste artigo fazem da categoria teórica conscientização não estiver equivocada, esta proposta de Freire poderá tornar-se referencial na formação acadêmica de docentes da disciplina Ensino Religioso. Como educar para cidadania diante de um quadro de negação de cidadania comum no cenário das escolas públicas brasileiras? Como educar para a tolerância em relação à diversidade se a realidade brasileira se mostra intolerante em diversas circunstâncias? Como promover direitos humanos quando os direitos humanos básicos são negados e ameaçados diariamente aos/as discentes das escolas públicas brasileiras? Como olhar para o outro e ser soliário se a solidariedade nem sempre é percebida na realidade das escolas públicas brasileiras? Como respeitar a religião do outro, se não houver uma conscientização de que vive-se um pluralismo religioso no ambiente escolar?

Conscientização como informado acima foi compreendida como uma palavra perigosa no cenário nacional nos idos de 1964. Tornou-se o motivo de exílio para Freire que propunha a leitura de mundo, antes da leitura da palavra. Conscientização não pode ser entedida como uma mera verbalização do verbo 
conscientizar. Não é possível afirmar que em função de ter consciência o sujeito iniciou seu ato de conscientização.

Este artigo se apropria do termo conscientização para descrever o possível processo pelo qual os/as docentes, enquanto sujeitos do processo de educar para libertar se conscientizam da realidade sociocultural que molda as vidas dos/as discentes e em que medida eles/as, os/as docentes, são capazes de transformar esta realidade sociocultural e oferecer aos/as discentes meios pelos quais eles substituam sua percepção ingênua e adotem uma atitude crítica. Para atuar desta forma o/a docente deve ser alfabetizado politicamente, em outras palavras, utilizando a categoria de Freire, deve alcançar a conscientização. Para que os/as discentes sejam sujetos autônomos.

\section{Desvendando o olhar: por um ensino que promova libertação}

Esta seção assume o lugar do Agir, pretendendo contribuir para desvendar o olhar. Propõe que a disciplina Ensino Religioso seja aplicada para promover libertação. Libertação de pré-concceitos, libertação de uma visão equivocada em relação ao outro ser humano com que interage. Entenda-se a noção de libertação, a partir do próprio Paulo Freire, que a aproxima da noção de humanização. Em suas palavras:

\footnotetext{
Desta maneira, o processo de alfabetização política - como o processo lingüístico - pode ser uma prática para a "domesticação dos homens", ou uma prática para sua libertação. No primeiro caso, a prática da conscientização não é possível em absoluto, enquanto no segundo caso o processo é, em si mesmo, conscientização. Daí uma ação desumanizante, de um lado, e um esforço de humanização, de outro. (FREIRE, 1979, p. 16).
}

Docentes da disciplina Ensino Religioso que tentam implementar uma abordagem de educação libertadora a partir da perspectiva de Paulo Freire precisarão ser pacientes. Conscientização pode ser um processo lento. De ambos os lados: dos/as docentes e também dos/as discentes. A libertação nunca pode ser 
imposta. A visão emancipatória de Paulo Freire pode revelar-se demasiadamente visionária e a sua educação para libertação, em última análise, muito arriscada. Ele usa uma maneira de apresentar a educação, não como um pacote de informação, mas como uma oportunidade de aprendizagem interativa que insiste na solidariedade crítica e no interesse de um aprendiz autônomo.

Por meio do processo de conscientização, outro nível de consciência crítica pode ser atingido. Para Freire, o aprendizado envolve todo o processo de conscientização da situação concreta, entender como essa situação pode ser alterada e agir para mudar a situação. Lecionar a disciplina Ensino Religioso. Ensinar envolve mais do que simplesmente transmitir os conteúdos programáticos. Ensinar os conteúdos programáticos da disciplina Ensino Religioso torna-se então um ato político, a conquista da consciência crítica como um meio de finalmente promover solidariedade em vez de intolerância.

Todos os seres humanos estão, em virtude de serem humanos, envolvidos em um processo de conscientização. O que muda é o contexto. Contudo, em contextos diferentes, ainda existem pontos de partida comuns e incluem a distinção, entre educação como instrumento de domesticação e educação como um instrumento de libertação.

Nenhuma forma de educar pode ser considerada neutra, como tampouco nenhuma instituição. Escolhas ideológicas institucionais são determinadas pela direção e são feitas em contextos específicos e quase sempre conflituosos, podendo ser mudadas em função de transformações conjunturais e, mais ainda, estruturais. Não há áreas cinzentas. Ou se educa para a libertação, autonomia do sujeito ou para a negação da libertação. Contudo, a escolha que devem fazer escolas públicas de ensino fundamental e docentes da disciplina Ensino Religioso é optarem por uma educação libertadora. É preciso buscar os elementos comuns em diferentes tradições religiosas de forma a demonstrar o aspecto distinto de cada tradição. 
As Ciências da Religião, ao se constituírem como uma das bases epistemológicas para o ER, contribuem para a compreensão do humano enquanto ser em/de busca, aberto à transcendência e históricoculturalmente situado dentro de referências religiosas, influenciadas por elas de múltiplas maneiras e, muitas vezes, agindo a partir delas. Nesse sentido, o estudo do fenômeno religioso num Estado laico, a partir de pressupostos científicos, visa à formação de cidadãos críticos e responsáveis, capazes de discernir a dinâmica dos fenômenos religiosos, que perpassam a vida em âmbito pessoal, local e mundial (FONAPER, 2008).

Tal abordagem terá como objetivo desenvolver um discente autônomo a partir da disciplina de Ensino Religioso; que seja consciente de sua realidade religiosa bem como das demais; que envolva docentes e discentes em um relacionamento baseado em parceria; que tenha uma nova compreensão do compromisso social e que ofereça caminhos construtivos para o desenvolvimento relacional.

\section{Conclusão}

Neste ponto, os leitores e leitoras podem questionar alguns aspectos relativos ao artigo. Quais serão os professores e as professoras da disciplina Ensino Religioso que conseguem conscientizar seus educandos e educandas para um senso de abertura dialogal e libertadora? Quais são as competências e habilidades que estes professores e professoras buscam para a formação dos/as educandos/as? Contudo, apesar de muito importante, seria necessária uma pesquisa, que não foi o objeto do artigo, para ofertar conclusões mais assertivas. Fica em aberto para novas incursões na temática.

O artigo pretendia mostrar como a obra de Paulo Freire pode ser importante para a disciplina Ensino Religioso. Este tema não é novo, sendo objeto de vários estudos acadêmicos (vide Catálogo de dissertações e teses da Capes), assim como em artigos (facilmente encontrados em periódicos qualificados). Tal quantidade de trabalhos reforça a importância de um educador que, nos dias atuais de obscurantismo político, tem sua obra negada. Paulo Freire, cristão (socialista?), 
levanta uma questão muito pertinente para os nossos dias, a saber: quem conscientiza quem? Ou melhor, quem é o sujeito da conscientização?

Neste momento que atravessamos na história brasileira e também da América do Sul e no mundo, o processo de conscientização pode ser dito indispensável em virtude do intenso processo de alienação que vem arraigando-se no mundo, em função do denominado consenso neoliberal, aprovado por causa da onipresença do capital em todas as áreas da vida das pessoas, na medida em que as mutações do processo de acumulação capitalista reduzem, cada vez mais, os ambientes de deliberação autônoma das pessoas e dos grupos sociais, notadamente dos oprimidos. O que poderia ser razoável esperar que um/a discente conhecesse das principais religiões do mundo quando terminarem os estudos na disciplina Ensino Religioso? Aprender sobre religião precisa ser um ato equilibrado com o aprendizado proveniente da própria religião. Noutras palavras, a questão-chave subjacente ao exercício do profissional de Ensino Religioso é qual o tipo de discente que se deseja ao final do processo: um/a discente autônomo ou oprimido.

\section{REFERÊNCIAS}

AFP. A Bíblia volta ao Palácio: poder político cristão ganha força na Bolívia. Exame, 13 nov. 2019. Disponível em: https://exame.abril.com.br/mundo/a-biblia-volta-ao-palaciopoder-politico-cristao-ganha-forca-na-bolivia/. Acesso em: 21 nov. 2019.

BRASIL. [Constituição (1988)]. Constituição da República Federativa do Brasil. Brasília: Supremo Tribunal Federal, 2019.

FONAPER. Parâmetros Curriculares Nacionais: Ensino Religioso. 7. ed. São Paulo: Ave-Maria, 2004.

FONAPER. Propostas de diretrizes curriculares nacionais para o curso de graduação em ciências da religião. Licenciatura em ensino religioso. 2008. Disponível em: http://www.fonaper.com.br/documentos_propostas.php. Acesso em: 25 nov. 2019.

FREIRE, Paulo. Conscientização: teoria e prática da libertação: uma introdução ao pensamento de Paulo Freire. São Paulo: Cortez \& Moraes, 1979. 
FREIRE, Paulo. Education: the practice of freedom. London: Writers and Readers Publishing Co-operative, 1976.

FREIRE, Paulo. A educação na cidade. 2. ed. São Paulo: Cortez, 1995.

FREIRE, Paulo. Educação como prática da liberdade. Rio de Janeiro: Paz e Terra, 1967.

FREIRE, Paulo. Pedagogia da indignação: cartas pedagógicas e outros escritos. São Paulo: UNESP, 2000.

FREIRE, Paulo. Pedagogia do oprimido. 42. ed. Rio de Janeiro: Paz e Terra, 2005.

FREIRE, Paulo; FREIRE, Nita; OLIVEIRA, Walter Ferreira de: Pedagogia da solidariedade: América Latina e educação popular. Indaiatuba: Vila das Letras. 2009.

G1. Bolsonaro anuncia professor e pastor Milton Ribeiro como novo ministro da Educação. 10 jul. 2020. Disponível em:

https://g1.globo.com/politica/noticia/2020/o7/10/bolsonaro-anuncia-professor-miltonribeiro-como-novo-ministro-da-educacao.ghtml. Acesso em: 25 nov. 2019.

GIROUX, Henry A. Prefácio. In: FREIRE, Paulo; FREIRE, Nita; OLIVEIRA, Walter Ferreira de. Pedagogia da solidariedade: América Latina e educação popular. Indaiatuba: Vila das Letras. 2009.

INSTITUTO BRASILEIRO DE GEOGRAFIA E ESTATÍSTICA. Censo Demográfico 2010. Características gerais da população, religião e pessoas com deficiência. Rio de Janeiro: IBGE, 2012.

LDB: Lei de diretrizes e bases da educação nacional. 2. ed. Brasília: Senado Federal, 2018. p. 23-24.

MARINHO, Andrea Rodrigues Barbosa. Paulo Freire e a conscientização. 2015. 166 f. Tese (Doutorado em Educação). Programa de Pós-Graduação em Educação, Universidade Nove de Julho, São Paulo.

MEC. Base Nacional Comum Curricular. MEC: Brasília, 2017.

OLIVEIRA, Fábio Falcão. História da educação: confessionalidade e (re)estruturação da igreja nos séculos XVI e XVII. Revista de Educação do Cogeime, ano 25, n. 48, p. 7592, jan./jun. 2016. 